\title{
Earthquake and Ambient Vibration Monitoring of the Steel-Frame UCLA Factor Building
}

\author{
Monica D. Kohler, ${ }^{\text {a) }}$ Paul M. Davis, ${ }^{\text {b) }}$ and Erdal Safak, ${ }^{c)}$ M.EERI
}

\begin{abstract}
Dynamic property measurements of the moment-resisting steel-frame University of California, Los Angeles, Factor building are being made to assess how forces are distributed over the building. Fourier amplitude spectra have been calculated from several intervals of ambient vibrations, a 24-hour period of strong winds, and from the 28 March 2003 Encino, California $\left(\mathrm{M}_{\mathrm{L}}\right.$ $=2.9)$, the 3 September 2002 Yorba Linda, California $\left(\mathrm{M}_{\mathrm{L}}=4.7\right)$, and the 3 November 2002 Central Alaska $\left(M_{w}=7.9\right)$ earthquakes. Measurements made from the ambient vibration records show that the first-mode frequency of horizontal vibration is between 0.55 and $0.6 \mathrm{~Hz}$. The second horizontal mode has a frequency between 1.6 and $1.9 \mathrm{~Hz}$. In contrast, the first-mode frequencies measured from earthquake data are about 0.05 to $0.1 \mathrm{~Hz}$ lower than those corresponding to ambient vibration recordings indicating softening of the soil-structure system as amplitudes become larger. The frequencies revert to pre-earthquake levels within five minutes of the Yorba Linda earthquake. Shaking due to strong winds that occurred during the Encino earthquake dominates the frequency decrease, which correlates in time with the duration of the strong winds. The first shear wave recorded from the Encino and Yorba Linda earthquakes takes about $0.4 \mathrm{sec}$ to travel up the 17-story building. [DOI: 10.1193/1.1946707]
\end{abstract}

\section{INTRODUCTION}

A prototype structural health monitoring program using a 17-story building has recently been implemented on the University of California, Los Angeles (UCLA) campus. The monitoring program comprises a full-scale, soil-structure interaction experiment using a steel frame building that is densely instrumented for strong motions. Dynamic properties that include measures of how forces are distributed over buildings during earthquakes are useful in the earthquake-resistant design of tall buildings and other structures (Jennings et al. 1972, Foutch 1978, Smyth et al. 2003). Earthquake vibration recordings can be used to validate and improve the dynamic models of structure shaking, and can serve as reference points for more complete calculations based on elastoplastic and other nonlinear force-deflection relationships (Trifunac 1970). To this end, we have

\footnotetext{
a) Center for Embedded Networked Sensing, University of California, Los Angeles, 3563 Boelter Hall, Los Angeles, CA 90095-1596

b) Dept. of Earth and Space Sciences, University of California, Los Angeles, 595 Charles E. Young Dr., Los Angeles, CA 90095-1567

${ }^{c}$ U.S. Geological Survey, 525 S. Wilson Ave., Pasadena, CA 91106
} 
recorded earthquake and ambient vibration waveforms in order to measure the horizontal and torsional fundamental frequencies and their time dependence, as well as mode shapes from building displacement.

The primary goal of this paper is to describe soil-building softening observations that are measurable for small, local earthquakes and for a period of strong winds. We also describe here the basic building shaking characteristics by comparing earthquake and ambient vibration data as one of the first steps in the long-term monitoring project. Key elements of this long-term effort will be to develop a database of measurements before a large future earthquake occurs in order to predict future earthquake building responses, to compare with actual earthquake building responses, to detect soil-structure interactions during large earthquakes, and to detect significant nonlinearities in the system response from large earthquakes to use in improving the building model and predictions of strong shaking.

As part of the vibration monitoring of the Factor building done to date, a large quantity of ambient vibration data and two small but significant local earthquakes were recorded that show temporal changes in vibration mode characteristics. Specifically, the frequencies of the first two modes of deformation are lower for small earthquakes than for ambient vibrations, but the frequencies increase to their previous pre-earthquake levels within minutes of the earthquake. Lowering of frequencies after earthquakes has been seen before in the Millikan Library (Foutch and Jennings 1978, Clinton and Heaton 2003), but our monitoring program illustrates how these changes can be continuously monitored to detect significant damage or breakage in a structure. It is generally assumed that nonlinear behavior is small unless a structure has experienced severe shaking from a large event. Our monitoring program has shown that measurable softening effects are occurring for small earthquakes due to changes in the stiffnesses of the soil-building system when amplitudes get larger. Recent equipment upgrades in the Factor building now make it possible to begin monitoring these time-dependent and amplitudedependent changes in real time in order to detect significant changes in system properties.

\section{THE FACTOR BUILDING}

The UCLA Doris and Louis Factor building, a 17-story moment-resisting steelframe structure with an embedded 72-channel accelerometer network, is the most heavily and densely instrumented building in North America (Figure 1). It was instrumented by the U.S. Geological Survey after the 1994 Northridge, California, earthquake. Previous to our efforts, the Factor building network served as a station in the U.S. Geological Survey National Strong Motion Program network, where triggered data were collected at frequent intervals by visiting the data loggers in person. During 2002-2003, it recorded continuous earthquake and ambient vibration data in real time from 24 channels distributed throughout the building. Work to connect all 72 channels to nine new Quanterra data loggers was completed in early 2004 subsequent to the completion of this manuscript.

The Factor building houses the UCLA Center for the Health Sciences, taking up 0.4 acres of area. It is composed of 198,000 sq. feet that make up laboratories, faculty 
a)

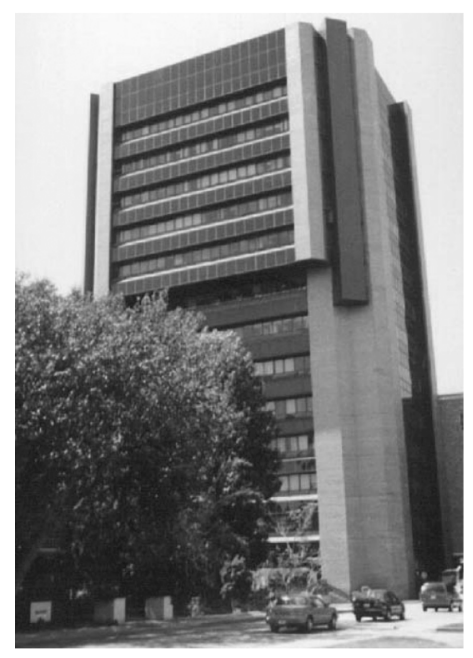

b)

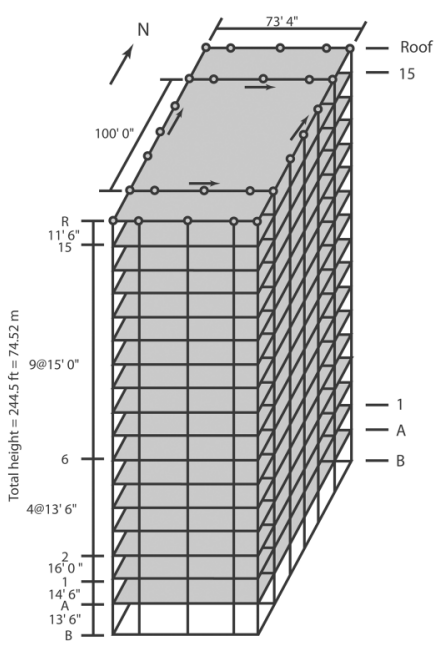

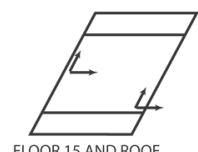
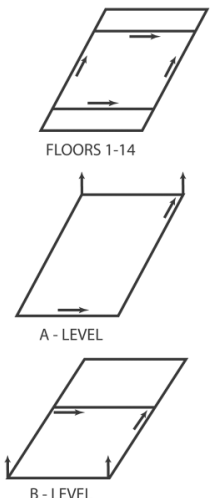

Figure 1. (a) Photo of Factor building taken from the northeast side of the building, and (b) diagram of Factor building sensor locations. Arrows show polarities of sensors on each floor.

offices, administrative offices, the School of Nursing, the School of Medicine, auditoriums, and classrooms. The building consists of two stories below grade and is set back at the north end to avoid shoring and underpinning of the existing adjacent UCLA Life Sciences building at the northwest corner. The building is approximately rectangular (longer in the north-south direction than in the east-west direction) and this partly contributes to the differing properties apparent in the orthogonal horizontal waveform recordings described later in this paper.

Factor building construction is steel frame type 1 as per the Uniform Building Code. Except for some concrete cassons, the structure is supported by concrete spread footing. The basement walls are reinforced concrete protected by waterproofing. The floor slabs are lightweight aggregate concrete conforming to ASTMC330 lightweight aggregates for structural concrete placed on metal decking. There is reinforcing steel conforming to ASTM A615 grade 60. The building has a clay brick veneer split 1.5" thick secured with metal anchors attached to metal slots. There are six elevators: two geared passenger elevators serve floors 1 through 8 at 4,000 lbs, two passenger elevators serve the basement to the 15 th floor at $4,000 \mathrm{lbs}$, and two service elevators serve the basement to the 14th floor at 3,000 lbs. The air conditioning system components are housed in equipment rooms on various floors. The machinery is mounted by means of isolation devices to minimize both vibration and acoustical disturbances.

Excavation of the soft soil below the site was required during building construction. During site preparation, a report on the site characteristics (see References for full report citation) found that the natural soils beneath the Factor building consist of silty sand, silt, clayey sand, clay, and sand. The natural soils are firm throughout. Existing fill soils, 


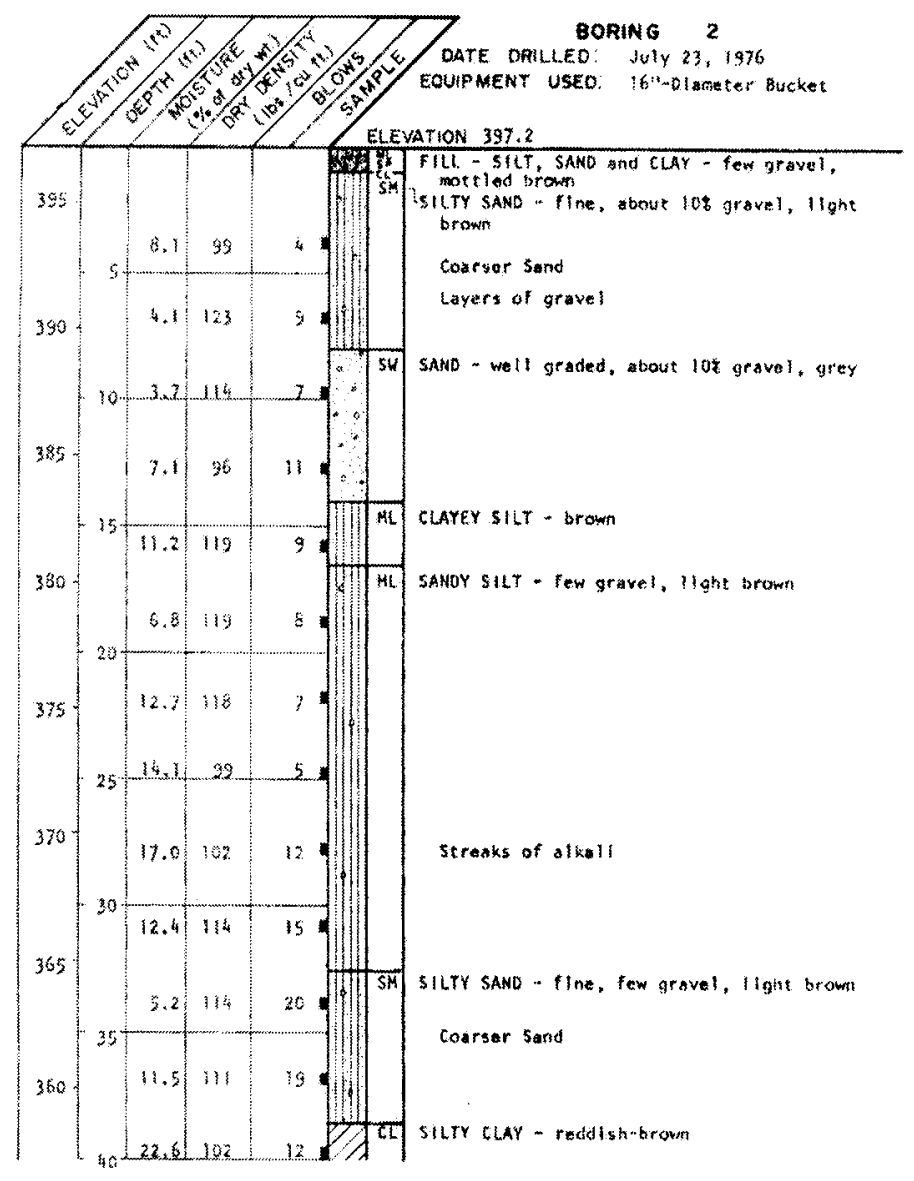

Figure 2. Profile of soil characteristics in one of three site preparation borings below the Factor building. The soil characteristics continue similarly to the maximum boring depth of about $30 \mathrm{~m}$. Profiles for the other two borings look similar. (LeRoy Crandall and Assoc. 1976).

$1 / 3$ to $3 \mathrm{~m}$ in thickness, consist of silt, sand, clay, and silty sand with some debris. Deeper and/or poorer quality fill probably occurs between locations. There is backfill adjacent to the existing buildings. Site investigation was done by drilling three borings to depths of 26 to $30 \mathrm{~m}$ below the existing grade. Figure 2 shows a typical soil cross section for one of the borings. A downhole seismic survey was performed as part of the site investigation to determine P-wave and S-wave soil velocities (Figure 3). P and S waves were recorded by a borehole seismometer with three orthogonal geophones. Layer thicknesses were determined from velocity data and known geometry. P-wave and S-wave velocities are $\sim 150 \mathrm{~m} / \mathrm{s}$ and $\sim 300 \mathrm{~m} / \mathrm{s}$ in the first few meters of the silty sandy soil. 


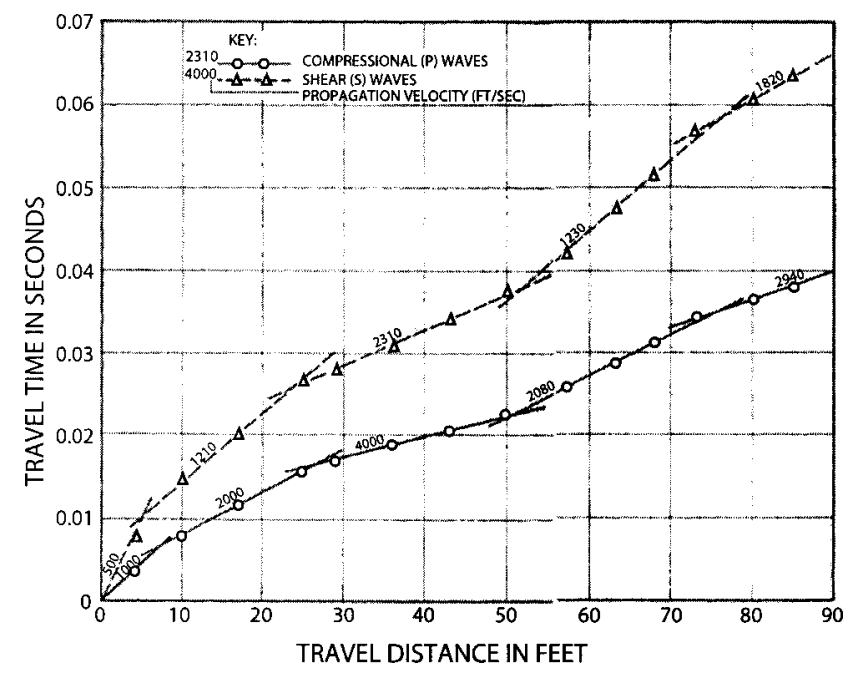

Figure 3. Profile of soil P-wave and S-wave velocities taken in site preparation borings below the Factor building. (LeRoy Crandall and Assoc. 1976).

\section{THE FACTOR BUILDING SEISMIC NETWORK}

The Factor building has a Kinemetrics FBA-11 accelerometer network composed of 4 horizontal channels per floor except for the basement and subbasement which have 2 vertical and 2 horizontal channels each (Figure 1). The horizontal sensors are oriented north-south and east-west along the midsections of most floors. The force-balance accelerometer sensors have a natural frequency of $50 \mathrm{~Hz}$, normal damping at $70 \%$ of critical, and a dynamic range of $135 \mathrm{~dB}$ from 0.01 to $50 \mathrm{~Hz}$. The output range scale is either $\pm 1 \mathrm{~g}$ or $\pm 2 \mathrm{~g}$, depending on the sensor. During 2002-2003, four Kinemetrics Altus Mt. Whitney recorders served as data loggers with A/D converters in the building's penthouse (the top floor, which serves as a large facilities and equipment space). GPS antennae are installed on the roof. The data loggers use a Brickwall FIR anti-aliasing filter with a cutoff at $80 \%$ of output Nyquist. The power sources for the data loggers and sensors are also located in the penthouse. The unique feature of this network is that data are being continuously streamed from many parts of the building along its height profile for real-time monitoring to our laboratory on campus.

In the summer and fall of 2001, as part of a seed project for the UCLA NSF Science and Technology Center for Embedded Networked Sensing, UCLA computer networking specialists installed a dedicated fiber optic internet connection to the Factor building in order to enable continuous data streams into other laboratories. Four device servers were connected to each of the four Mt. Whitney recorders for data conversion into Ethernet format. A real-time monitoring software package has been used for the past year at the UCLA seismology laboratory to monitor data flow. Six channels per Mt. Whitney data 
logger are continuously streamed via the Internet at 100 sps. The 24 channels are distributed throughout the building and are providing a good sampling of building motion from the ground to near the top floor.

\section{DATA AND OBSERVATIONS}

We have recorded excellent strong-motion records from two nearby earthquakes, the 28 March 2003 Encino, California, $\mathrm{M}_{\mathrm{L}}=2.9$ and the 3 September 2002 Yorba Linda, California, $M_{L}=4.7$ earthquakes, since continuous recording of Factor data began. The 3 November $2003 \mathrm{M}_{\mathrm{w}}=7.9$ Central Alaska earthquake was also clearly recorded by the accelerometer network in spite of a predominance of low-frequency $(<0.5 \mathrm{~Hz})$ energy. In addition, we have examined ambient vibrations of the Factor building at different times of day and seasons in order to monitor changes in building response. The results are being used to monitor the state of health of the building, and to demonstrate and evaluate the potential of methods to detect degradation with time or during an earthquake.

For the earthquake and ambient vibration time series recordings and Fourier amplitude spectra described in this paper, the signal processing was carried out the same way on each record in order to make appropriate comparisons. For each event, a time series of $100 \mathrm{sec}$ was selected that contained either the local earthquake record or the ambient vibration recording. The records were bandpass filtered with a two-pass Butterworth filter using a wide range of cutoff frequencies to examine the corresponding spectra. Prior to obtaining the spectra, the data were windowed using a Hanning window with a side lobe width of $0.1(10 \%)$.

The prominent spectral peaks of the first translational mode were identified by fitting a Gaussian to the frequency peak and locating the center of the Gaussian. In nearly all cases, the central frequency could have been accurately determined directly from the spectrum by eye alone, but we use the Gaussian fit for a more quantitative measure. Here we focus on spectra with cutoff frequencies of 0.1 and $5.0 \mathrm{~Hz}$, and further narrow bandpass filter when measuring the centers of the vibrational mode frequency peaks. The frequency range was specifically chosen to show the critical lowest natural frequencies of building vibration and their relationship with soil-structure interactions through changes in amplitude. The exception to the processing rules is the Central Alaska earthquake where most of the energy in the longer teleseismic recordings was from low-frequency surface waves.

\section{EARTHQUAKE RECORDS}

On 28 March 2003 at GMT 5:44 a.m. (27 March 2003 at 9:44 p.m. local time), a small earthquake with $\mathrm{M}_{\mathrm{L}}=2.9$ was felt in the San Fernando Valley, north of downtown Los Angeles and the UCLA campus (Figure 4). It occurred two miles south of the city of Encino and was widely felt on the west side of Los Angeles. Though this earthquake was small, it was felt as a sharp jolt in the UCLA campus area, $9 \mathrm{~km}$ southeast of the epicenter. This earthquake was recorded on 24 channels of the Factor building's continuous network (Figure 5a). 


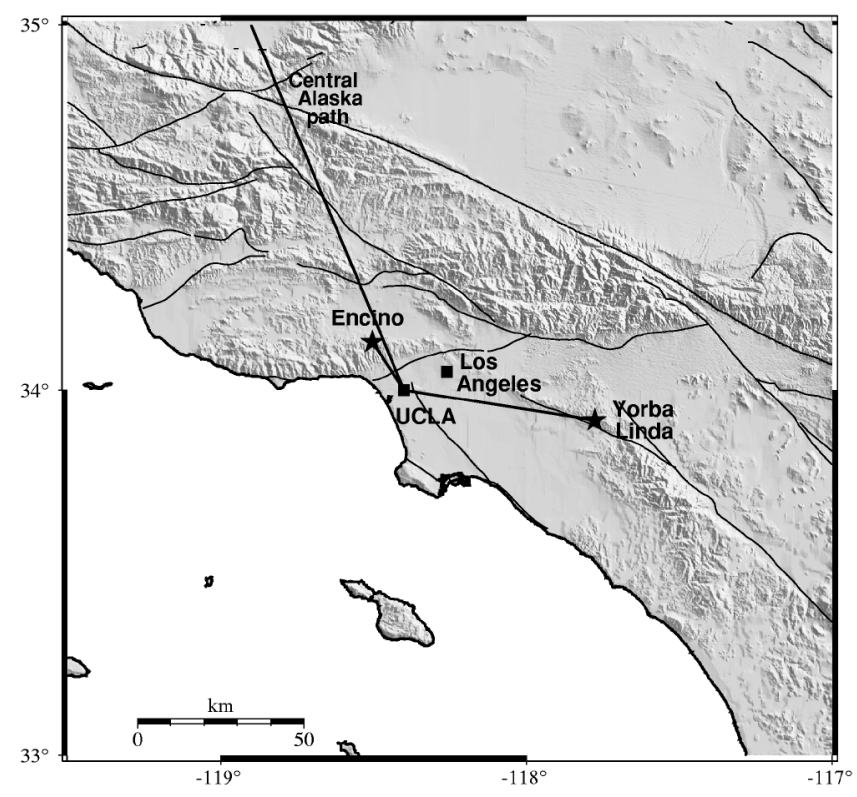

Figure 4. Map showing locations and back azimuths of the three earthquakes. Squares show locations of UCLA campus and downtown Los Angeles. Stars show locations of Encino and Yorba Linda earthquakes. Lines indicate surface-projected raypaths (the great circle path in the case of the Central Alaska earthquake).

Another significant local earthquake recorded by the Factor building sensors occurred on 3 September 2002 at GMT 7:08 a.m. (12:08 a.m. local time) near Yorba Linda, California, with $\mathrm{M}_{\mathrm{L}}=4.7$. The main shock occurred northeast of Yorba Linda in Orange County at a distance of $64 \mathrm{~km}$ east of UCLA (Figure 4). It was preceded by two small foreshocks the day before and followed by 23 aftershocks during the next nine hours. The main shock was produced by strike-slip faulting on a vertical fault. The earthquake occurred either on a jog of the Whittier fault or on a small conjugate fault adjacent to the Whittier fault. The main shock shook the Orange County and Inland Empire areas, and was felt as far as the High Desert region and Escondido. The peak intensity was Modified Mercalli V, enough to wake up sleepers and knock items off shelves, but is not thought to have caused any structural damage. This earthquake occurred early in the Factor building system setup when a subset of the data loggers was reserved for continuous monitoring. Thus, only 18 channels captured this event (Figure 5b).

Preliminary mode identification has been made based on examination of the earthquake spectral data (Figure 6). The frequencies of the peaks shown in Figure 6 are displayed in Table 1. The central frequency measurements of the first mode were obtained by further narrow bandpass filtering $(0.45$ to $0.65 \mathrm{~Hz})$ the accelerations and carrying out a least-squares fit of a Gaussian at the spectral peak. Investigation of horizontal displacement within narrow frequency bands was also conducted to verify the first three modes and their shapes. Narrow bandpass filters were applied to the time series and the 
(a)

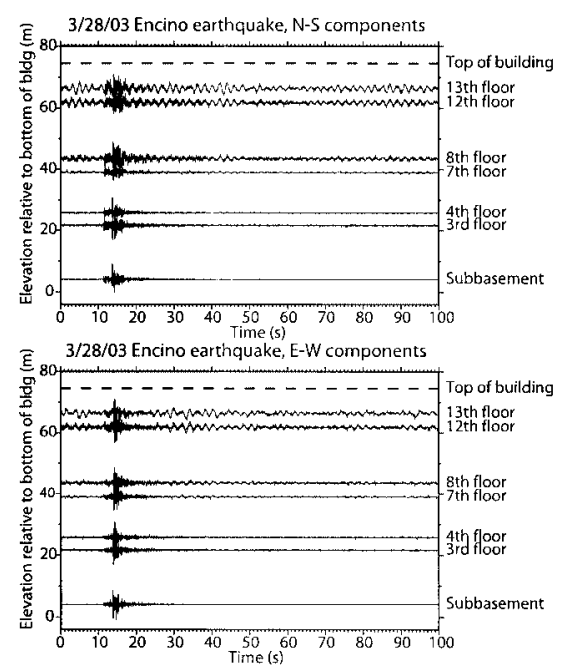

(b)
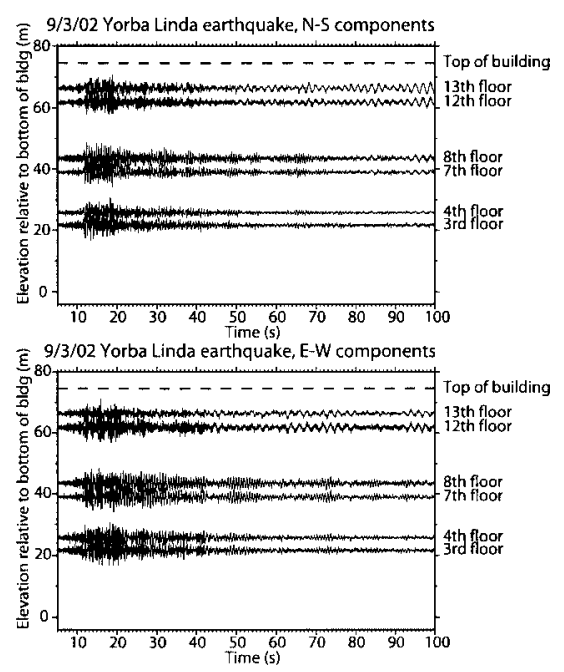

Figure 5. (a) Encino earthquake accelerations and (b) Yorba Linda earthquake accelerations. The time series were bandpass filtered for frequencies from 0.1 to $5.0 \mathrm{~Hz}$ and normalized to the maximum acceleration in each trace.

simultaneous displacement was determined for each floor. Displacement was obtained by integrating the acceleration records twice after bandpass filtering, demeaning, detrending, and decimating the time series by four (for a new Nyquist frequency of $12.5 \mathrm{~Hz}$ ). Figure 7 shows the results of the maximum displacement measurements for the Encino earthquake. Displacements for the Yorba Linda earthquake look very similar. In Figure 7 the mode shapes were normalized such that they all have the same maximum displacement, though in reality some modes have larger maximum displacements than others. The figure shows displacement for the north-south (N-S) components (top row) and east-west (E-W) components (bottom row) of the first three horizontal modes. We show values from the N-S component sensors located nearest the east side of the building and the E-W component sensors located on the north side. The opposite sides of the building show very similar results.

The earthquake Fourier amplitude spectra demonstrate that different modes of the Factor building are excited at different amplitudes for different earthquakes (Figure 6). After being struck by earthquake waves, the building resonates for hundreds of seconds, well after the direct earthquake waves have ceased. The reverberations show characteristic beat patterns, possibly a surface-wave effect. From the spectra for the Encino earthquake, several peaks are apparent and correspond to the first few modes. The first sharp peak occurs at $0.52 \mathrm{~Hz}$ in the N-S components and at $0.50 \mathrm{~Hz}$ in the E-W components. The corresponding peaks for the Yorba Linda earthquake are 0.57 and $0.51 \mathrm{~Hz}$. This is the fundamental frequency of vibration for the building. The next more diffuse peak in this group occurs at $\sim 0.7 \mathrm{~Hz}$ for both the N-S and E-W components of the Encino and 
a)
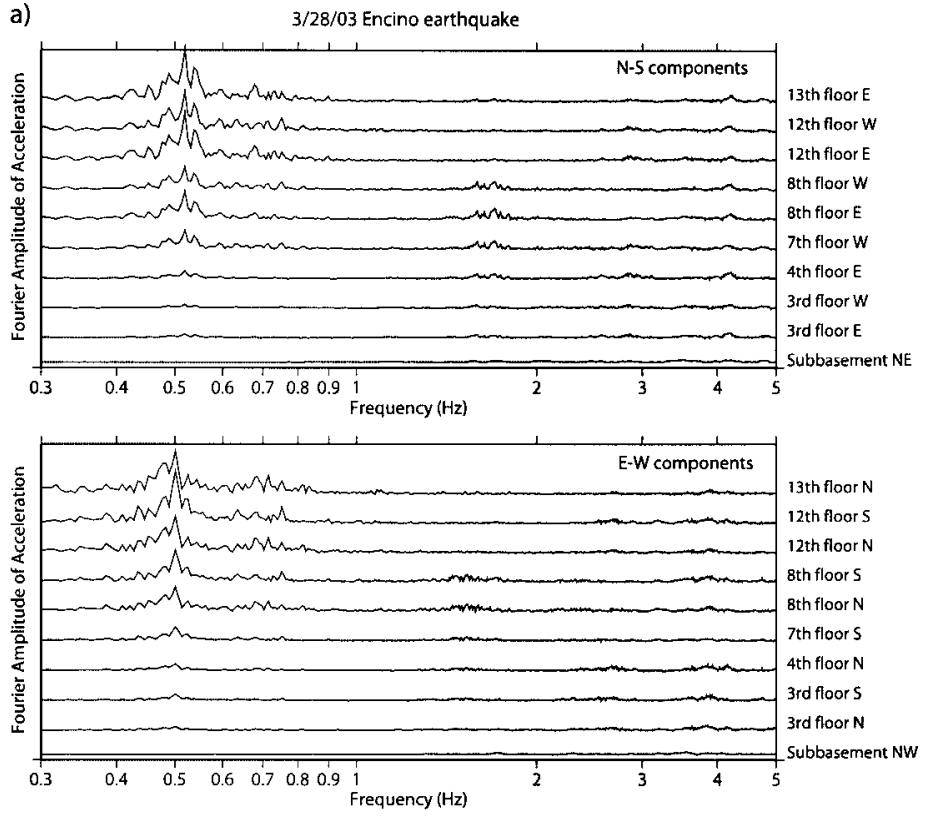

b)

9/3/02 Yorba Linda earthquake
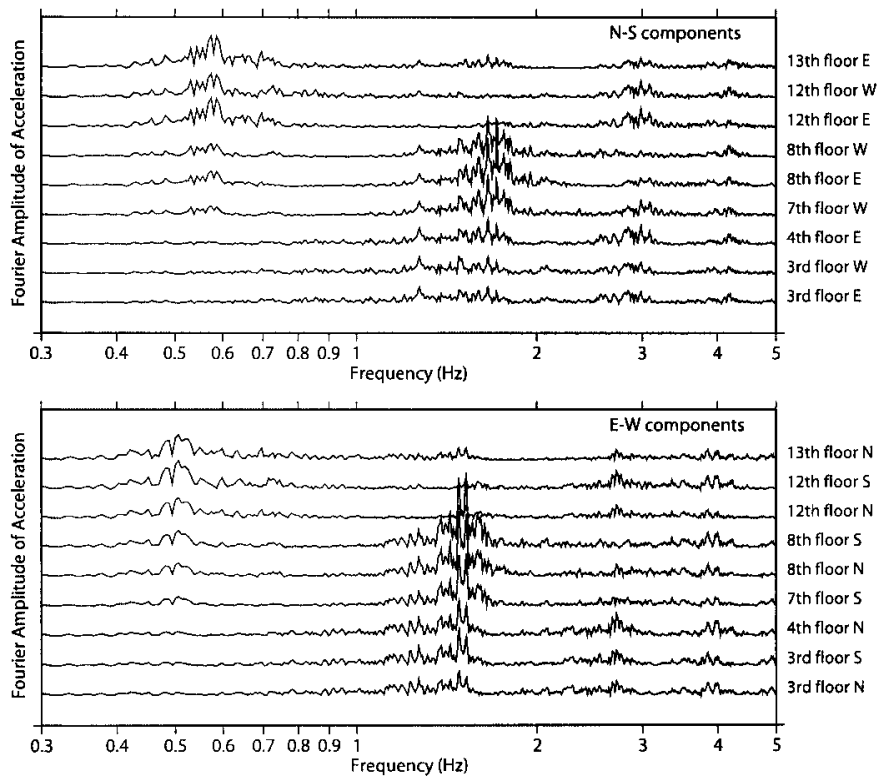

Figure 6. (a) Encino earthquake Fourier amplitude spectra and (b) Yorba Linda earthquake Fourier amplitude spectra. The corresponding time series were bandpass filtered for frequencies from 0.1 to $5.0 \mathrm{~Hz}$. The spectra have been normalized relative to the maximum spectral amplitude in their respective plots. 
Table 1. Preliminary mode identification for the 28 March 2003 Encino, California, and the 3 September 2002 Yorba Linda, California, earthquakes. The first-mode central frequency peak was made by fitting a Gaussian after bandpass filtering the acceleration records with cutoff frequencies of 0.45 and $0.65 \mathrm{~Hz}$, and calculating the Fourier amplitude spectra. The values for the first torsional mode, and the second and third horizontal modes are estimates.

\begin{tabular}{lcccc}
\hline \hline Earthquake & $\begin{array}{c}\text { First } \\
\text { horizontal } \\
\text { mode }(\mathrm{Hz})\end{array}$ & $\begin{array}{c}\text { First } \\
\text { torsional } \\
\text { mode }(\mathrm{Hz})\end{array}$ & $\begin{array}{c}\text { Second } \\
\text { horizontal } \\
\text { mode }(\mathrm{Hz})\end{array}$ & $\begin{array}{c}\text { Third } \\
\text { horizontal } \\
\text { mode }(\mathrm{Hz})\end{array}$ \\
\hline Encino N-S & 0.52 & $\sim 0.7$ & $1.50-1.80$ & $2.70-3.05$ \\
Encino E-W & 0.50 & $\sim 0.7$ & $1.40-1.65$ & $2.45-2.80$ \\
Yorba Linda N-S & 0.57 & $\sim 0.7$ & $1.60-1.75$ & $2.75-3.10$ \\
Yorba Linda E-W & 0.51 & $\sim 0.7$ & $1.45-1.55$ & $2.65-2.85$ \\
\hline \hline
\end{tabular}

Yorba Linda earthquakes; this is the fundamental torsional mode. The second group of peaks for the Encino earthquake occurs between 1.50 and $1.80 \mathrm{~Hz}$ in the N-S components, and between 1.40 and $1.65 \mathrm{~Hz}$ in the E-W components. These values are 1.60 and $1.75 \mathrm{~Hz}$ in the N-S direction and 1.45 and $1.55 \mathrm{~Hz}$ in the E-W direction for the Yorba Linda earthquake. This is the second horizontal mode of the building. The frequency measurements for the earthquakes are summarized in Table 1.

Contrary to the local earthquake recordings, waveforms from the 3 November 2002 Central Alaska earthquake $\left(\mathrm{M}_{\mathrm{w}}=7.9\right.$; epicentral distance $\left.=35^{\circ}\right)$ (Figures 4 and 8) show the dominant effect of the surface waves on the building and its sensors. The surface waves are lower in frequency than the fundamental frequency of the building and demonstrate how the building is uniformly affected by the long-wavelength waves. Spectra from the Central Alaska earthquake (Figure 8) reveal that the low-frequency waves from that event, which are outside the building resonance bands, have similar amplitudes on every floor. The building rides with the ground as a rigid body.

We have demonstrated the feasibility of recording data at 100 samples per second, allowing us to trace the passage of the seismic waves as they move from the base of the building to the top. Figure 9a shows the horizontal velocity seismograms that occurred on different floors of the Factor building during the Encino earthquake. There is a first prominent pulse of velocity that occurs at the base of the building at about $13.6 \mathrm{~s}$ in the record. This pulse can be observed to propagate up the building and it arrives near the top about $0.4 \mathrm{~s}$ later. Figure $9 \mathrm{~b}$ shows similar travel-time data for the Yorba Linda earthquake. Since the basement floors did not record the Yorba Linda earthquake, the pulse origin time at the bottom of the building has to be extrapolated. Though the Factor building network includes GPS receivers, accurate timing information from GPS was not recorded as part of the continuous monitoring due to hardware and software limitations. Thus, the accuracy in the timing of the shear waves through the building is based on the accuracy of the internal Mt. Whitney clocks. 

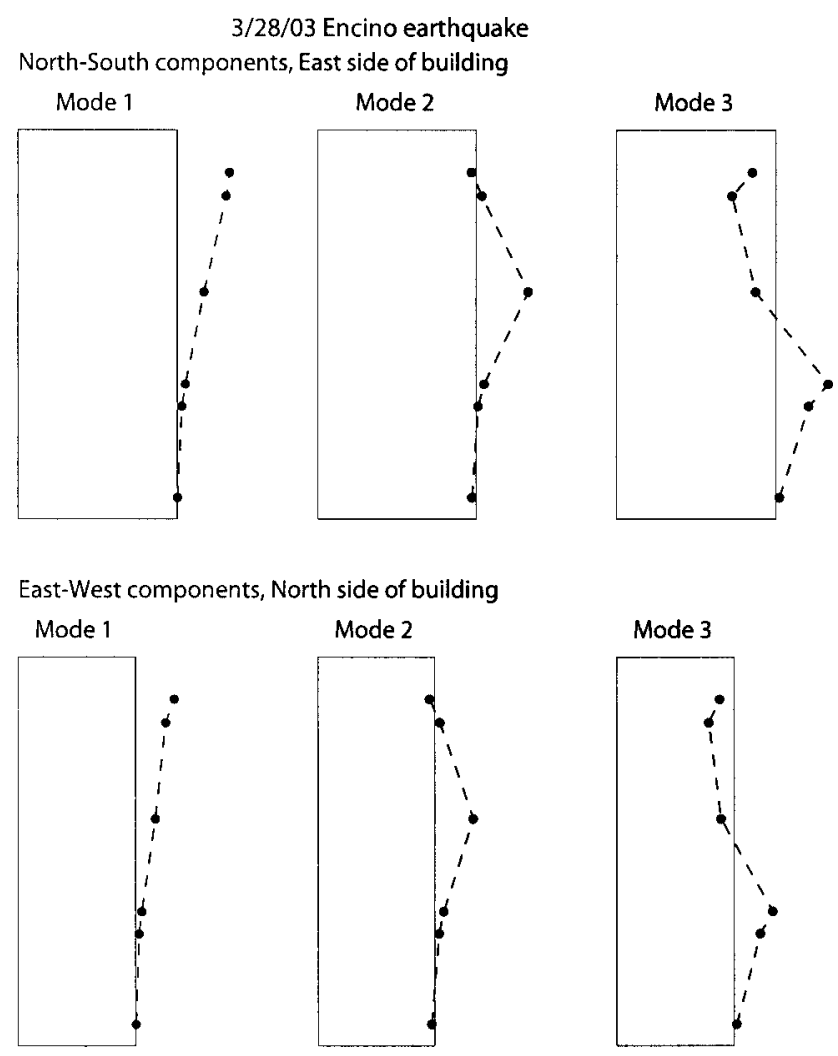

Figure 7. Maximum displacement plots for Encino earthquake from narrow bandpass filtered time series. Plot shows displacement for the first three horizontal modes: N-S components (top row) and E-W components (bottom row). Displacements were normalized to the same maximum value for each mode. The building is shown for height scale.

\section{AMBIENT VIBRATIONS}

Ambient vibration recordings have been collected continuously from the 24 channels since late 2002, 24 hours a day. Frequent periodic review of the ambient vibrations continues to take place in order to check for state-of-health issues related to the system, as well as to investigate the dynamic response of the building to nonseismic vibrations. In particular, reviews have taken place almost daily of two periods of ambient vibrations at 3 a.m. and 3 p.m. These times were chosen because they reflect two contrasting recording environments. At 3 a.m. the building is at one of its quietest periods, with little activity inside or outside on adjacent streets. This is also one of the coolest periods of the day, when air conditioners are running at a minimum, if at all. At 3 p.m., the building is at one of its busier periods with activity taking place in labs, clinics, and classrooms. Street noise levels from traffic and construction are high, and in summer this is the hottest time of day, when air conditioners are running at or near a maximum. Occasionally during windy conditions, especially during the Santa Ana wind conditions in which 

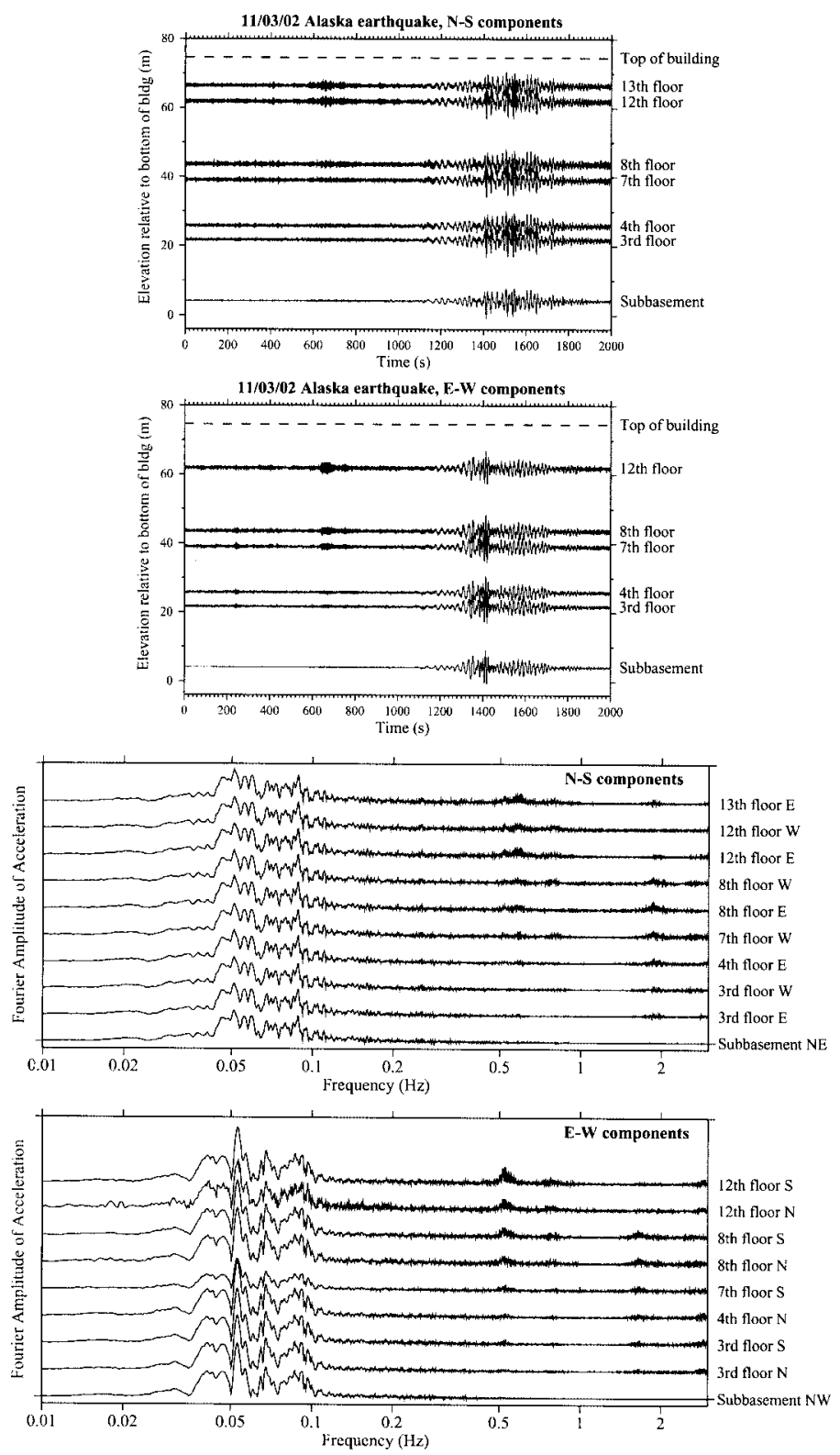

Figure 8. Central Alaska earthquake accelerations and Fourier amplitude spectra. The time series were bandpass filtered for frequencies from 0.01 to $3.0 \mathrm{~Hz}$, and normalized to the maximum acceleration in each trace. One 13th floor recording with low signal-to-noise ratio was removed from the plot. The spectra have been normalized relative to the maximum spectral amplitude in the plot. 
(a)
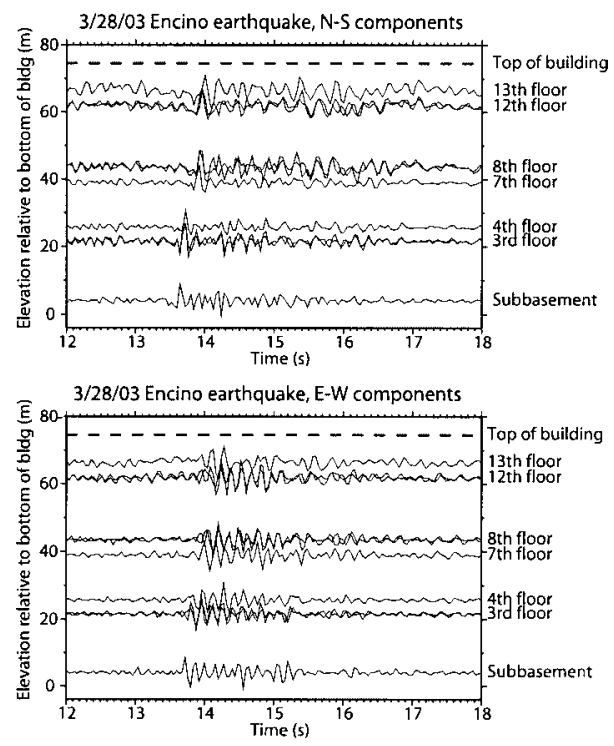

(b)
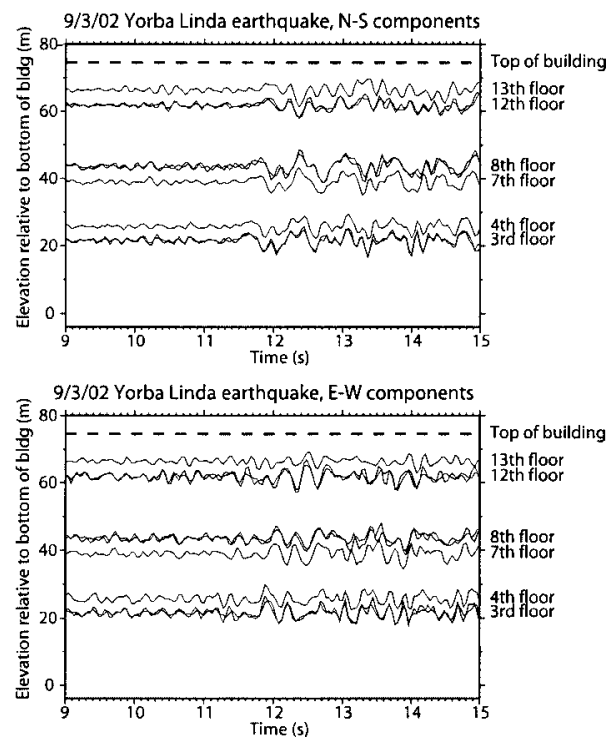

Figure 9. (a) Encino earthquake velocity records and (b) Yorba Linda earthquake velocity records showing shear wave traveling up building. The time series were bandpass filtered for frequencies from 0.1 to $12.0 \mathrm{~Hz}$ and normalized to the maximum acceleration in each trace.

warm, dry winds blow from the east or northeast, wind speeds can reach up to 35 knots. Gusts can be as high as 100 knots. The strongest Santa Ana winds tend to occur during the night and early morning hours due to the absence of a sea breeze. These conditions usually take place in late fall and early winter.

In Figure 10 we show two sets of ambient vibration Fourier amplitude spectra from accelerations recorded on 28 March 2003 and 22 July 2003 around 3 a.m., when conditions were among the quietest. Upon inspection of these and more than 50 additional examples of 2002 and 2003 data from 3 a.m. and 3 p.m. that look extremely similar to those displayed in Figure 10, consistent characteristics in the spectra have become apparent that are independent of time of day, year, non-extreme weather, etc. Specific frequencies peaking in the spectra are always about the same from day to day and month to month, in particular those associated with the natural frequencies of vibration. The relative amplitudes, however, change frequently and are probably due to hourly and daily variations in internal or external sources of vibrations.

Preliminary mode identification has been made based on examination of the ambient vibration data. The frequencies of the peaks shown in Figure 10 as well as several additional days throughout the year are displayed in Table 2 . They were measured using the same processing techniques as for the local earthquake data. Figure 11 shows the (typical) Gaussian fits to the first-mode spectral peak used to determine the central frequency. As with the earthquake data, investigation of horizontal displacement within narrow fre- 

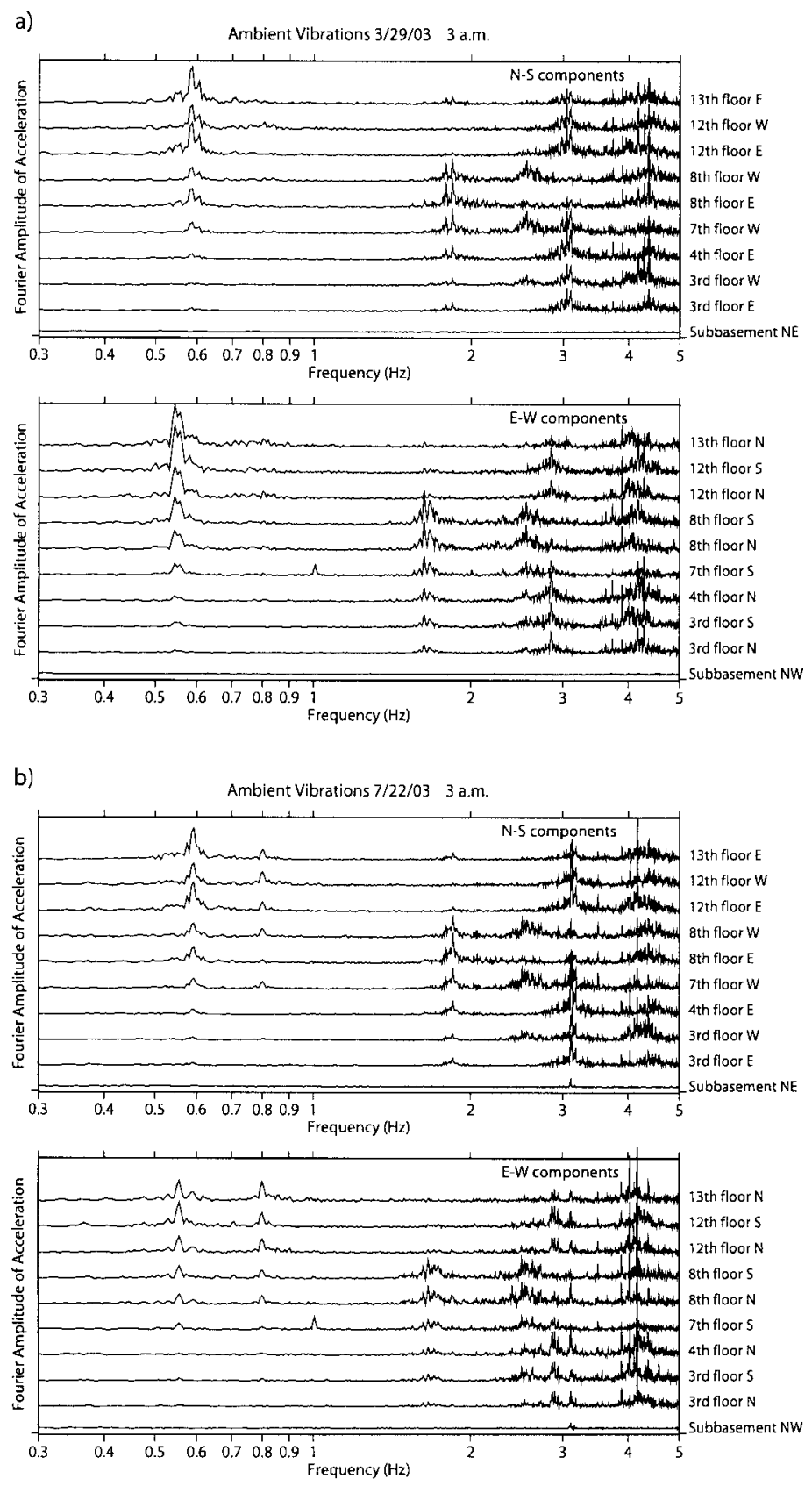

Figure 10. Ambient vibration Fourier amplitude spectra recorded at 3 a.m. on (a) 28 March 2003 (about 6 hours after the Encino earthquake) and (b) 22 July 2003. The time series were bandpass filtered for frequencies from 0.1 to $5.0 \mathrm{~Hz}$. The spectra have been normalized relative to the maximum spectral amplitude in their respective plots. 
Table 2. Preliminary mode identification for ambient vibration recordings made at $3 \mathrm{a}$.m. (local time) on 16 November 2002, and 28 March, 28 May, 4 June, and 22 July 2003. The first-mode central frequency peak was made by fitting a Gaussian after bandpass filtering the acceleration records with cutoff frequencies of 0.45 and $0.65 \mathrm{~Hz}$, and calculating the Fourier amplitude spectra. The values for the first torsional mode and the second and third horizontal modes are estimates. A dash means that the measurement could not be made.

\begin{tabular}{lcccc}
\hline \hline $\begin{array}{l}\text { Ambient } \\
\text { vibration } \\
\text { recording }\end{array}$ & $\begin{array}{c}\text { First } \\
\text { horizontal } \\
\text { mode (Hz) }\end{array}$ & $\begin{array}{c}\text { First } \\
\text { torsional } \\
\text { mode }(\mathrm{Hz})\end{array}$ & $\begin{array}{c}\text { Second } \\
\text { horizontal } \\
\text { mode (Hz) }\end{array}$ & $\begin{array}{c}\text { Third } \\
\text { horizontal } \\
\text { mode (Hz) }\end{array}$ \\
\hline 16 November 2002 N-S & 0.58 & - & $1.70-1.95$ & $2.95-3.25$ \\
16 November 2002 E-W & 0.54 & - & $1.50-1.70$ & $2.70-3.00$ \\
28 March 2003 N-S & 0.58 & 0.80 & $1.70-1.95$ & $2.95-3.15$ \\
28 March 2003 E-W & 0.54 & 0.80 & $1.50-1.70$ & $2.75-2.90$ \\
28 May 2003 N-S & 0.58 & 0.81 & $1.70-1.90$ & $3.00-3.20$ \\
28 May 2003 E-W & 0.55 & 0.81 & $1.60-1.75$ & $2.75-2.95$ \\
4 June 2003 N-S & 0.60 & 0.80 & $1.70-1.95$ & $3.00-3.20$ \\
4 June 2003 E-W & 0.56 & 0.80 & $1.55-1.75$ & $2.80-3.00$ \\
22 July 2003 N-S & 0.59 & 0.80 & $1.75-1.90$ & $3.05-3.20$ \\
22 July 2003 E-W & 0.55 & 0.80 & $1.60-1.80$ & $2.80-3.00$ \\
\hline \hline
\end{tabular}

quency bands was conducted to verify the modes and their shapes. As before, narrow bandpass filters were applied to each of the first three modes and the simultaneous displacement was determined for each floor. Displacement was obtained as before by integrating the acceleration records twice after bandpass filtering, demeaning, detrending, and decimating the time series by four. Figure 12 shows the results of the maximum displacement measurements for the 22 July 2003 ambient vibrations whose spectra are shown in Figure 10. Again, the mode shapes were normalized such that they all have the same maximum displacement. The figure shows displacement for the N-S components (top row) and E-W components (bottom row) of the first three horizontal modes.

Figure 10 also shows the coupling that occurs between the orthogonal components due to the asymmetry of the building. There are usually smaller peaks at frequencies near the dominant frequency in one set of horizontal components that correspond to the primary peak in the orthogonal direction (Figure 10). The E-W peaks, for example, often appear in the N-S data and vice versa. The peaks always occur at lower frequencies in the shorter E-W direction than for the longer N-S direction for the horizontal modes. The torsional modes do not show the same sets of peaks due to coupling, since they incorporate both directions in the building motion.

Upon comparison of mode frequencies for the earthquakes (Table 1) with the ambient vibration records (Table 2), the frequencies for the ambient vibrations are consistently higher for each specific mode. Comparing the Encino earthquake with ambient vibrations for the first (fundamental) mode, the earthquake frequency peak for the N-S components $(0.52 \mathrm{~Hz})$ is approximately 12 percent lower than the average first-mode frequency peak $(0.59 \mathrm{~Hz})$ for the ambient vibrations. The E-W horizontal mode frequen- 
(a)
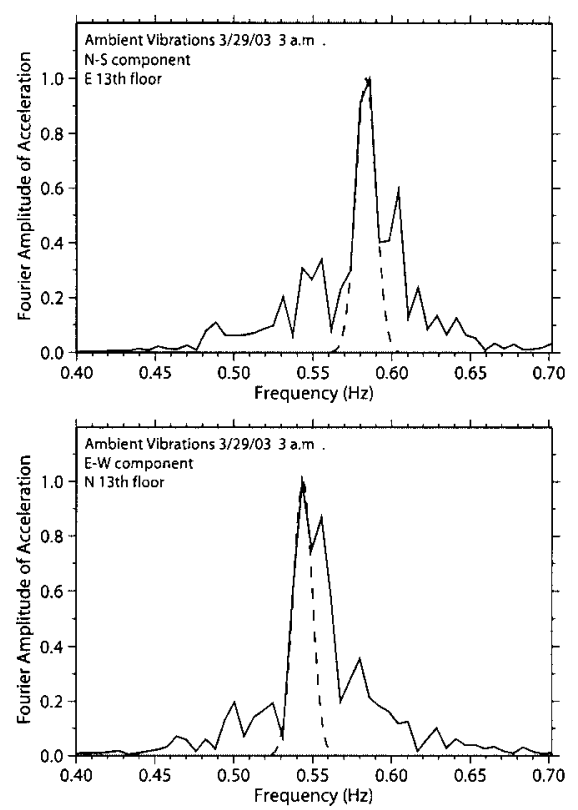

(b)
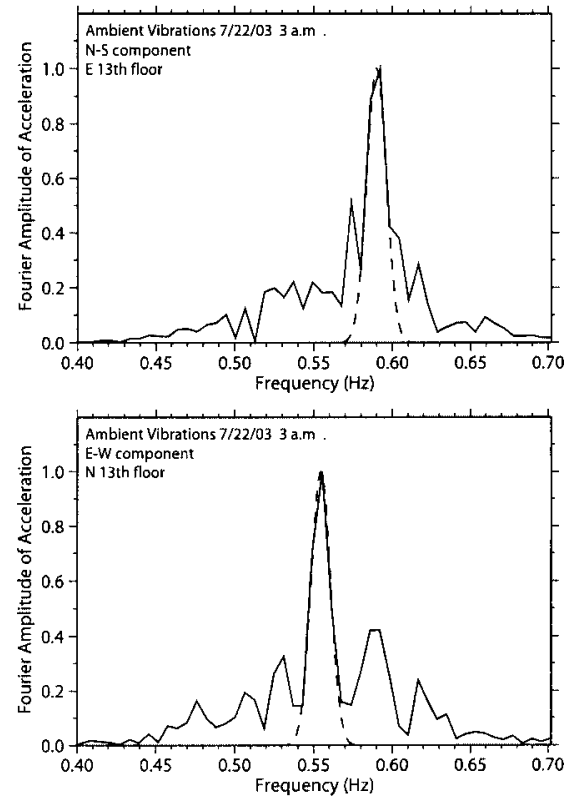

Figure 11. Least-squares Gaussian fits to the first-mode spectral peaks used to find the central frequencies shown in Table 2. Solid lines are data, dashed lines are fits. These fits were typical of the ambient vibration records.

cies behave similarly. The first torsional mode frequency peak for the Encino earthquake $\mathrm{N}-\mathrm{S}$ components $(\sim 0.7 \mathrm{~Hz})$ is approximately 12 percent lower than the corresponding peak for ambient vibrations $(0.80 \mathrm{~Hz})$, and the E-W components behave similarly. While the peaks of the second modes are more difficult to identify, they display a general behavior that is consistent with the first-mode frequency decrease for earthquakes. In both the Encino and Yorba Linda earthquake cases, the second-mode frequencies are approximately 7 percent lower than for the corresponding ambient vibration modes. These observations require further study as more local earthquake data are recorded by the Factor network. Of course, the frequency decreases may not be significant if they are simply due to random fluctuations in frequencies, but the systematic decrease with increased amplitude shaking suggests that the phenomenon is real.

Two primary effects cause mode frequencies to decrease during earthquakes: nonlinearities in the system and soil-structure interactions. We first set out to show if our observed frequency decrease was due to soil-structure interaction effects (e.g., Jennings and Bielak 1972). It is important to quantify these effects so that the building is not erroneously assumed to be a fixed-based structure where foundation level recordings are taken as the base excitation for dynamic modeling purposes. In our case, as in most cases, no nearby free-field surface or downhole records exist that can be used as truly independent input. In order to determine if the source of the frequency decrease with the 

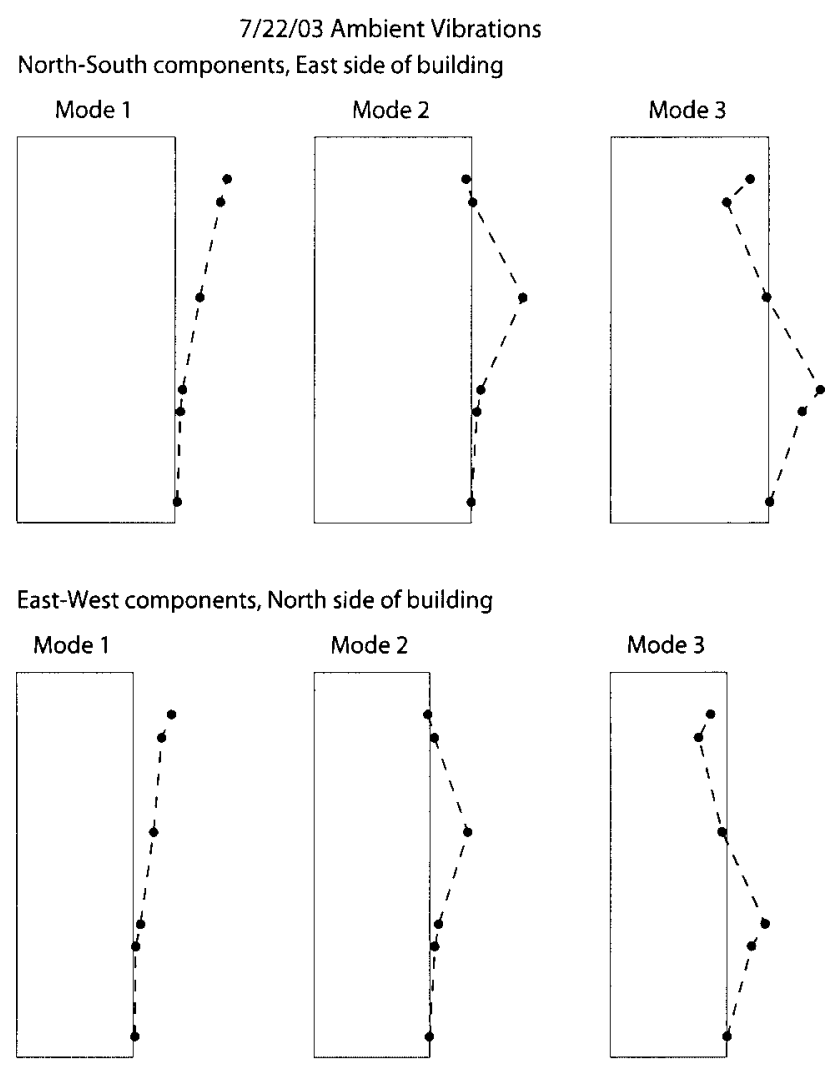

Figure 12. Maximum displacement plots for the 22 July 2003 ambient vibration time series. Plot shows displacement for the first three horizontal modes: N-S components (top row) and E-W components (bottom row). Displacements were normalized to the same maximum value for each mode. The building is shown for height scale. Plots of maximum displacement for other periods of ambient vibrations look almost identical.

earthquakes was soil-structure interaction, we calculated spectral ratios for the Encino earthquake. Fundamental frequencies of buildings influenced by soil vibrations are generally lower than those of the building not subjected to soil-structure interactions. This follows from the equations of motion for a two-degree-of-freedom linear system involving a foundation and a building with negligible rocking (Safak 1995). The presence of soil-structure interaction can be detected by comparing the dominant frequency of the top story to foundation spectral ratio with that of the Fourier amplitude spectrum of the top-story response (Safak 1995). The spectral ratio of the top story to foundation accelerations should reflect the frequency behavior of the fixed-base building (i.e., not subjected to soil-structure interactions), whereas the Fourier amplitude spectrum of the topstory response shows the frequency behavior with soil-structure interaction. The spectral ratio between the recording made at the 13th floor and the subbasement for the Encino earthquake was not found to reflect the higher, fixed-base frequencies, suggesting that 


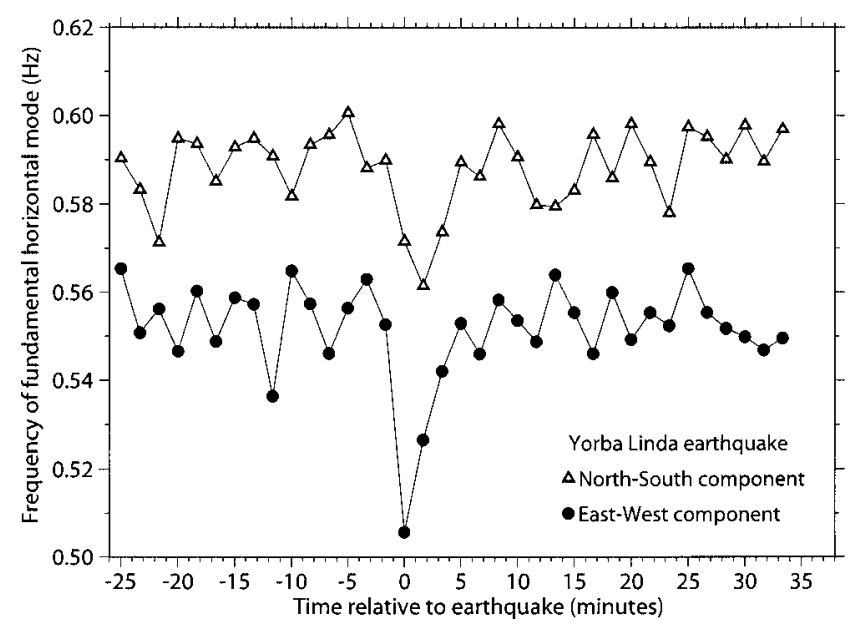

Figure 13. Change in fundamental horizontal mode natural frequency before and after the Yorba Linda earthquake. The frequency peaks were measured from 100-second acceleration segments from either 12th or 13th floor waveforms before and after the earthquake, bandpass filtered for frequencies between 0.45 and $0.65 \mathrm{~Hz}$. A least-squares fit to a Gaussian was used to find the central frequency peak.

soil-structure interaction may not be the sole cause of the observations. Note we could not do this with the Yorba Linda earthquake because it was not recorded by any floors lower than the third floor.

The other possibility is that the decrease is due to softening of the building or soilbuilding system that arises when it is shaken. During a large earthquake, the nonlinear behavior of a building reflected in the mode frequency changes is thought to be caused by failure, and large or small damage and breakages in structural elements. After large earthquakes, buildings may never revert to pre-earthquake behavior due to loss of rotational and translational stiffness (Foutch and Jennings 1978). Additional observations indicate that recovery can be near-instantaneous for minor earthquake shaking and normal ambient condition changes (Clinton and Heaton 2003). We have been able to document through monitoring that the Factor building reverted to pre-earthquake values for the first few modes of vibration within minutes of the relatively small Yorba Linda earthquake. In order to show this, we took several hours of data before and after the earthquake, and plotted the spectra for successive 100-second time series segments of either 12 th or 13th floor waveforms. The records were narrow bandpass filtered $(0.45$ to $0.65 \mathrm{~Hz})$ to measure the frequencies as described previously. A least-squares fit of a Gaussian function was used to determine the center of the frequency peak of the first horizontal mode. We find that the frequency reverts to pre-earthquake ambient vibration levels within 5 minutes after the Yorba Linda earthquake has occurred (Figure 13). 


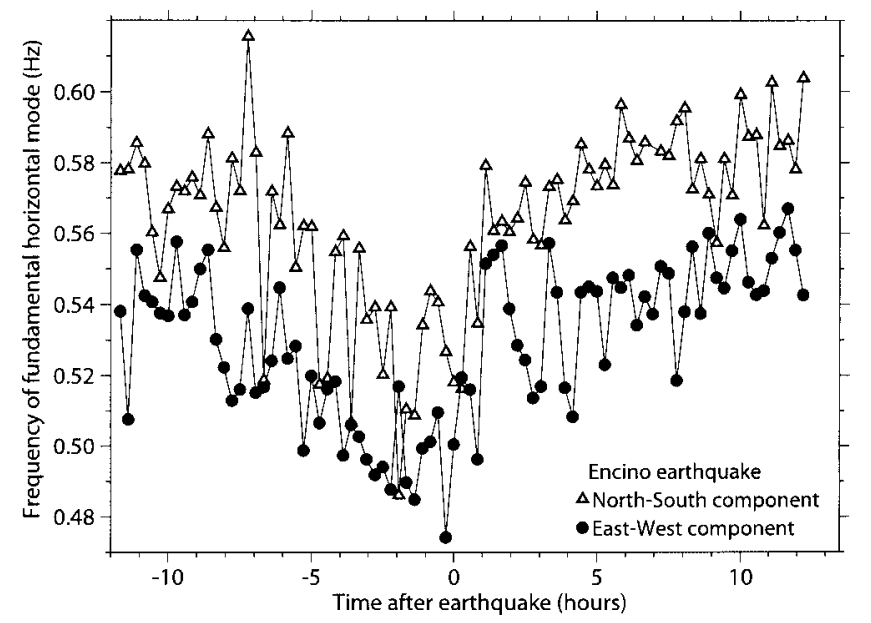

Figure 14. Change in fundamental horizontal mode natural frequency before and after the Encino earthquake. The frequency peaks were measured from 100-second acceleration segments from either 12th or 13th floor waveforms before and after the earthquake, bandpass filtered for frequencies between 0.45 and $0.65 \mathrm{~Hz}$. A least-squares fit to a Gaussian was used to find the central frequency peak.

The Encino earthquake presents a more complicated set of environmental circumstances. For the Encino earthquake, we find frequencies revert to ambient vibration levels after about six hours, but they were also low several hours before the Encino earthquake (Figure 14), an effect not explained solely by earthquake shaking. Upon examination of local climate data, we find that the duration of the low frequencies before and after the Encino earthquake correlates closely with the duration of some of the strongest winds recorded on the UCLA campus in that entire year. We obtained climate data collected by the UCLA Atmospheric Sciences Department at the nearby Math Sciences building that includes 10-minute recording intervals of wind (Figure 15). Two types of wind recordings are made: the first is an average of the last minute of data recorded during that particular 10-minute interval, and the second is a maximum wind speed recorded during the entire 10-minute interval (closer to a gust recording). In an examination of wind speeds recorded between August 2002 and September 2003, nearly the highest wind speeds were recorded 27 and 28 March 2004, coincident with the occurrence of the Encino earthquake (Figure 15). Factor building seismic data for the days before 27 March are not available to further extend the correlation analysis with wind speed data. We interpret the frequency decrease illustrated in Figure 14 to be the result of increased amplitudes due to a combination of the Encino earthquake and strong winds.

The temporary decrease in frequencies is a display of temporary nonlinear behavior that only shows up when the soil-building system is reacting to increased stresses of excitation. The frequency decrease reflects the reaction of the soil-building stiffnesses in 

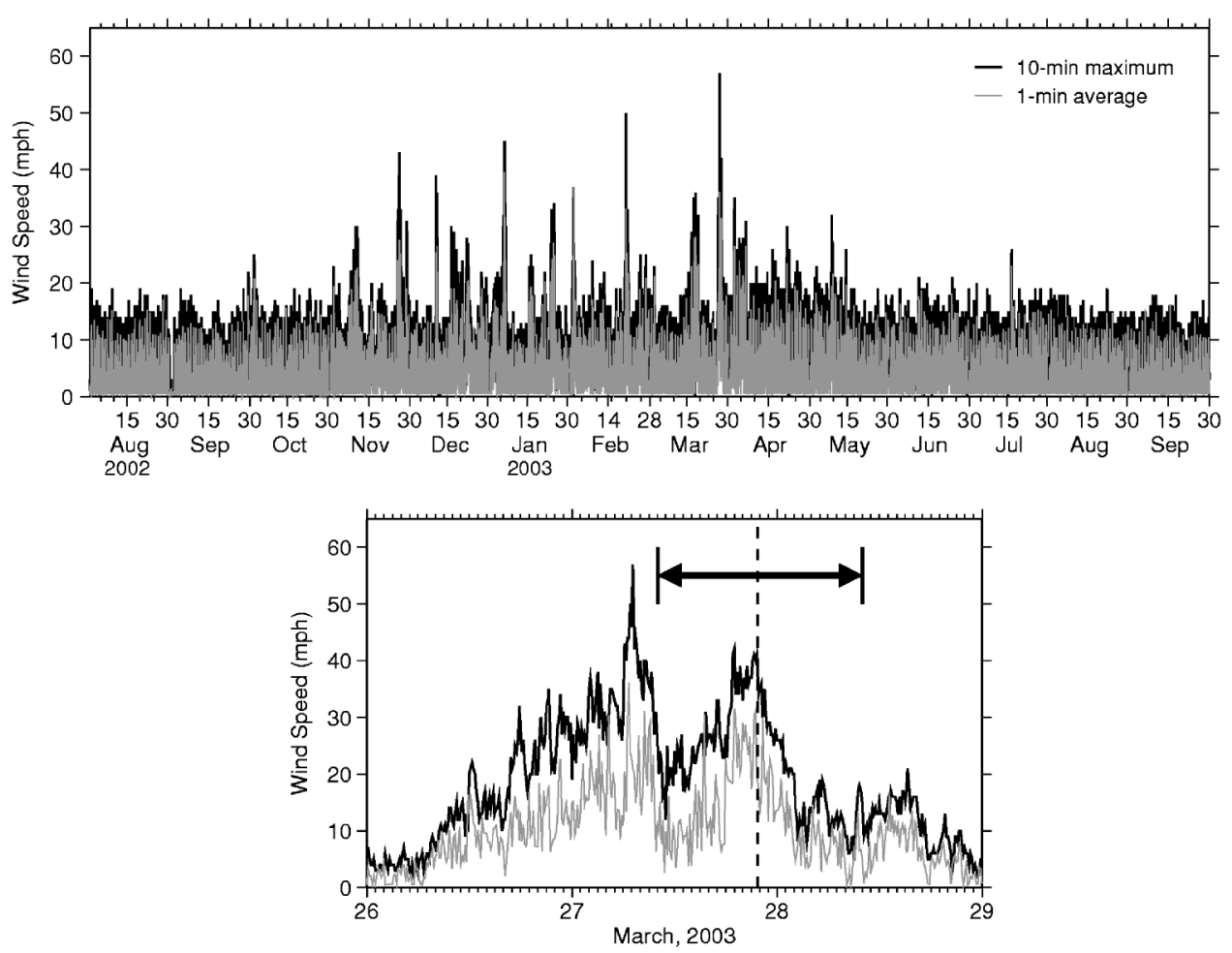

Figure 15. Wind speed data recorded in 10-minute intervals at the nearby UCLA Math Sciences building. " $1-$ min average" stands for the average wind speed recorded during the last minute of the 10-minute recording interval, and "10-min maximum" stands for the maximum wind speed recorded during a particular 10-minute interval (closer to a wind gust). The top plot shows wind speeds recorded over a year spanning 2002 and 2003. The bottom plot shows a blowup of three days in March (26-28 March 2003) when wind speeds were at or near their highest levels for the entire year. In the bottom plot, the horizontal line segment with arrows shows the time interval for which first-mode frequencies were measured from Factor building Fourier amplitude spectra (Figure 14). The vertical dashed line shows the date-time of the Encino earthquake.

response to increased stresses of the earthquake. If changes in building properties are primarily responsible for these observations, then softening of the building during earthquakes may be mainly due to the effects of nonstructural components such as walls and partitions. Nonstructural components act as a part of the structural system under low amplitude motions, providing additional stiffness. When the amplitudes get larger, they separate from the main system. 


\section{CONCLUSIONS}

The densely instrumented UCLA Factor building lies at the heart of a long-term structural monitoring program whose goals are to detect, assess, and locate possible structural damage. In preparation for the long-term analysis of vibration signals and dynamic property calculations, a database of Factor building measurements has been collected and analyzed. Fourier amplitude spectra have been calculated from several intervals of ambient vibrations, a 24-hour period of strong winds, and several earthquakes. Measurements made from the ambient vibration records show that the first-mode frequency of horizontal vibration is between 0.55 and $0.6 \mathrm{~Hz}$, while the second horizontal mode has a frequency between 1.6 and $1.9 \mathrm{~Hz}$. In contrast, the first-mode frequencies measured from earthquake data are about 0.05 to $0.1 \mathrm{~Hz}$ lower than those corresponding to ambient vibration recordings, indicating softening of the soil-building system as amplitudes become larger. The frequencies revert to pre-earthquake levels within 5 minutes of the 3 September 2002 Yorba Linda, California, $\left(M_{L}=4.7\right)$ earthquake. Shaking due to strong winds that occurred during the 28 March 2003 Encino, California, $\left(\mathrm{M}_{\mathrm{L}}=2.9\right)$ earthquake dominates the frequency decrease, which correlates in time with the duration of the strong winds.

Though it may not be critical to know if a building has reverted to pre-earthquake linear behavior within minutes for small earthquakes, what is unique is our ability to calculate the parameters associated with changes in modes of deformation. This has been done for several points along the building profile in order to observe timedependent and amplitude-dependent changes in the soil-structure system. We have set up a monitoring system in preparation for a large earthquake during which it may be necessary to make immediate critical decisions about building safety. The network was recently upgraded so that all 72 channels are streaming in real time at $500 \mathrm{sps}$ for modal analysis as well as identification of local breakage events. Over the next year, the network will be augmented by a borehole accelerometer to be installed within a few tens of meters of the Factor building. This makes the Factor building, one of the world's most densely instrumented real-time monitored structures, an ideal structural health monitoring prototype.

\section{ACKNOWLEDGMENTS}

The authors thank UCLA Vice Chancellor Peccei for advancing funds to install fiber optic network cable in the Factor building, Max Kopelevich for setting up the Factor network connection, Igor Stubailo for continued maintenance of the network, Chuck Conrad and Norman Wright in the UCLA Capital Programs office, Arnie Acosta for providing instrumentation information, Tom Heaton and John Wallace for discussions, Lucy Jones for use of USGS Pasadena office facilities, and James Murakami for UCLA Atmospheric Sciences Department climate data. This work was supported by the Center for Embedded Networked Sensing (NSF STC award \#CCR-0120778). 


\section{REFERENCES}

Clinton, J. F., and Heaton, T. H., 2003. Is there a linear building transfer function for small excitation? EOS Trans. Am. Geophys. Union 84 (46), Fall Meet. Suppl., Abstract S51E-0102.

Foutch, D. A., 1978. The vibrational characteristics of a twelve-story steel frame building, Earthquake Eng. Struct. Dyn. 6, 265-294.

Foutch, D. A., and Jennings, P. C., 1978. A study of the apparent change in the foundation response of a nine-story reinforced concrete building, Bull. Seismol. Soc. Am. 68, 219-229.

Jennings, P. C., and Bielak, J., 1972. Dynamics of Building-Soil Interaction, EERL 72-01, Earthquake Engineering Research Laboratory, California Institute of Technology, Pasadena, $55 \mathrm{pp}$.

Jennings, P. C., Matthiesen, R. B., and Hoerner, J. B., 1972. Earthquake Eng. Struct. Dyn. 1, $107-132$.

LeRoy Crandall and Associates Consulting Geotechnical Engineers, 1976. Report of Foundation Investigation and Site Response Study, Proposed Cancer Center/School of Nursing, Tiverton and South Circle Drives, Los Angeles, California for the University of California, Los Angeles, Campus Capital Programs building archives, University of California, Los Angeles.

Safak, E., 1995. Detection and identification of soil-structure interaction in buildings from vibration recordings, J. Struct. Eng. 121, 899-906.

Smyth, A. W., Pei, J.-S., and Masri, S. F., 2003. System identification of the Vincent Thomas suspension bridge using earthquake records, Earthquake Eng. Struct. Dyn. 32, 339-367.

Trifunac, M. D., 1970. Ambient Vibration Test of a Thirty-Nine Story Steel Frame Building, EERL 70-02, Earthquake Engineering Research Laboratory, California Institute of Technology, Pasadena, $40 \mathrm{pp}$.

(Received 9 December 2003; accepted 26 September 2004) 